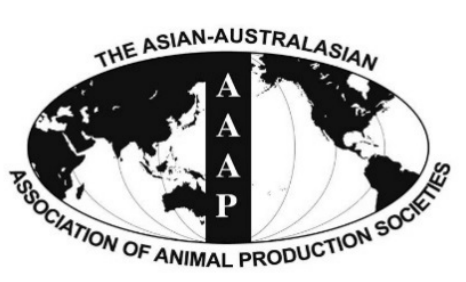

Open Access

Asian Australas. J. Anim. Sci.

Vol. 29, No. 12 : 1796-1804 December 2016

http://dx.doi.org/10.5713/ajas.15.0996

www.ajas.info

pISSN 1011-2367 elSSN 1976-5517

\title{
Negative Trends in Transport-related Mortality Rates in Broiler Chickens
}

\author{
Vladimir Vecerek, Eva Voslarova*, Francesca Conte ${ }^{1}$, Lenka Vecerkova, and Iveta Bedanova \\ Department of Animal Protection, Welfare and Behaviour, Faculty of Veterinary Hygiene and Ecology, \\ University of Veterinary and Pharmaceutical Sciences Brno, Brno 612 42, Czech Republic
}

\begin{abstract}
The high incidence of deaths during transport for slaughter is associated with poor welfare and represents a considerable loss to the poultry industry. In the period from 2009 to 2014, all shipments of broiler chickens to poultry processing plants were monitored in the Czech Republic and the numbers of chickens transported and those dying as a result of their transport were recorded and analysed. Overall transport-related mortality of broiler chickens transported for slaughter in the Czech Republic was $0.37 \%$. It ranged from $0.31 \%$ to $0.72 \%$, the increase approximately corresponding to the increasing transport distance. Statistically highly significant $(\mathrm{p}<0.001$ ) differences were found when comparing transport-related mortality rates in individual seasons of the year. The greatest mortality $(0.55 \%)$ was associated with transports carried out in winter months whereas the lowest death losses $(0.30 \%)$ were found in chickens transported for slaughter in summer months. Our study revealed greater transport-related mortality rates in broiler chickens transported for slaughter in the Czech Republic than expected when considering earlier studies. The most pronounced increases were found in transports for shorter distances and in winter months. However, an increase was found at all transport distances monitored except for distances exceeding 300 $\mathrm{km}$ and all seasons except for summer. Furthermore, a general increasing tendency in chicken losses during the monitored period was found. The particularly alarming finding is that the mortality of broiler chickens being transported to processing plants has been showing a long-term increasing tendency over the last two decades. Further research should focus on the identification of specific factors leading to such high and growing mortality rates and developing practical guidelines to improve the welfare of the birds in transit accordingly. (Key Words: Mortality, Poultry, Transport, Distance, Season, Welfare)
\end{abstract}

\section{INTRODUCTION}

Transportation is an essential component of the poultry industry, and can cause different degrees of stress to birds, ranging from mild discomfort and aversion to death (Schwartzkopf-Genswein et al., 2012). The rate of birds dying as a result of their transportation links to poultry welfare during transport to processing plants. The proportion of broiler chickens dead on arrival (DOA) has been reported to vary from around $0.15 \%$ (Mitchell, 2006) or $0.19 \%$ (Gregory and Austin, 1992) to values as high as $0.25 \%$ (Vecerek et al., 2006), 0.35\% (Bianchi et al., 2006; Petracci

\footnotetext{
* Corresponding Author: Eva Voslarova. Tel: +42-0-541562773, Fax: +42-0-541562790, E-mail: voslarovae@vfu.cz

${ }^{1}$ Department of Veterinary Sciences, University of Messina, Polo Universitario dell'Annunziata, viale Annunziata, Messina 981 68, Italy.

Submitted Dec. 4, 2015; Revised Jan. 6, 2016; Accepted Jan. 12, 2016
}

et al., 2006) or even up to $0.46 \%$ (Nijdam et al., 2004) or $0.67 \%$ (Fries and Kobe, 1992) within a load in Europe.

Many factors could influence the effects of transportation on welfare, among which the microclimate within the transportation truck was reported as the major cause of mortality (Schwartzkopf-Genswein et al., 2012). The effect of ambient temperature and relative humidity is to be considered in different seasons of the year in different regions since it may differ geographically. Vieira et al. (2011a) reported DOA rates of $0.42 \%$ for the summer and $0.39 \%, 0.28 \%$, and $0.23 \%$ for the spring, winter and autumn seasons, respectively, for transportation in the tropical conditions of Brazil. Alshawabkeh and Tabbaa (1997), in a study of mortality and losses during the transportation of broiler chickens from farms to processing plants in Jordan, found a mortality rate of $0.40 \%$. Aral et al. (2014) reported transport-related mortality averages in broiler chickens of $0.41 \%$ in Turkey. Tabbaa and Alshawabkeh (2000), in an

Copyright $@ 2016$ by Asian-Australasian Journal of Animal Sciences This is an open-access article distributed under the terms of the Creative Commons Attribution Non-Commercial License (http://creativecommons.org/licenses/by-nc/3.0/), which permits unrestricted non-commercial use, distribution, and reproduction in any medium, provided the original work is properly cited. 
examination of the conditions, and the interaction of conditions, affecting preslaughter damage and mortality to broilers during transport, found a significant relationship between the time of year and mortality rate. Bird DOA rate of $0.35 \%$ was reported by Whiting et al. (2007) as an average loss during 198 broiler deliveries in Canada, which were mainly associated with high summer ambient temperatures and loading density of the trailers. Petracci et al. (2006) reported average incidence of DOA to be 0.35 in broiler chickens transported to Italian poultry processing plants. However, the season significantly influenced the transportrelated mortality of broiler chickens, with higher incidence being observed during the summer $(0.47 \%)$. Knezacek et al. (2010) reported much higher DOA rates, specifically $0.7 \%$ to $1.4 \%$ for four journeys conducted during a Saskatchewan winter in Western Canada. Vecerek et al. (2006) found greater mortality of broiler chickens transported for slaughter in the Czech Republic in both summer and winter months in comparison to transports carried out in spring and autumn.

Death rates in poultry have been shown to be influenced also by the transport time and distance travelled (e.g., Nijdam et al., 2004; Oba et al., 2009). Warriss et al. (1992) investigated mortality in broiler chickens in relation to the length of journey to processing plants. In journeys lasting less than four hours, the incidence of dead birds was $0.16 \%$; for longer journeys the incidence was $0.28 \%$. Aral et al. (2014) found that mortality rates in broiler chickens transported for slaughter in Turkey ranged from $0.29 \%$ in journeys lasting less than two hours to $0.46 \%$ for journeys lasting more than ten hours. Similarly, Vecerek et al. (2006) found transport-related mortality rates of broiler chickens growing with increasing transport distances. Although only a $0.15 \%$ death rate was observed when broiler chickens were transported over distances up to $50 \mathrm{~km}$, considerably higher death rates of up to $0.86 \%$ were found when travel distances exceeded $300 \mathrm{~km}$. Voslarova et al. (2007) reported mortality rates in broiler chickens ranging from $0.15 \%$ to $0.68 \%$ in correlation to the distance travelled, i.e. lowest for distances below $50 \mathrm{~km}$, greatest for distances exceeding $300 \mathrm{~km}$. On the contrary, no effect of transport distance was observed in a study carried out to estimate the extent of DOA in poultry broiler production in the main producing regions of France (Chauvin et al., 2011). However, only moderate transport distances ( $75 \mathrm{~km}$ in average) were recorded in this study, much shorter than in the above-mentioned studies.

The aim of the present study was to assess mortality related to the commercial transport of broiler chickens for slaughter in the Czech Republic, to determine the effect of transport distance and season (ambient temperature) on the chicken mortality and, in addition, to identify developmental trends in the numbers of broiler chickens dying in the process of being transported for slaughter in the monitored period.

\section{MATERIALS AND METHODS}

In the period from 2009 to 2014, transport of broiler chickens to poultry processing plants was monitored in terms of the protection of animals against cruelty in the Czech Republic. The inspectors of the State Veterinary Administration of the Czech Republic recorded the numbers of broiler chickens transported to processing plants for slaughter. The veterinary inspectors recorded the mortality in these chickens in relation to transport, i.e. the number of chickens having died directly in the means of transport or having died in the processing plant after transport. The data for the whole Czech Republic was collected in database form in the Information Centre of the State Veterinary Administration. The data was analysed with a programme specially created for these purposes, which generated upon request from this database the reports about the numbers of transported broilers having died and converted them into Excel format for further statistical processing.

The impact of the transport distance on broiler chicken mortality in relation to transport to the processing plants was determined in such a way that the transport distances were divided into distances of up to $50 \mathrm{~km}, 51 \mathrm{~km}$ to $100 \mathrm{~km}, 101$ $\mathrm{km}$ to $200 \mathrm{~km}, 201 \mathrm{~km}$ to $300 \mathrm{~km}$, and above $300 \mathrm{~km}$. For these transport distances, the annual numbers of transported chickens and the annual numbers of chickens having died were recorded in absolute numbers and mortality levels in percentages were calculated for the period from 2009 to 2014.

Seasonal impact, shown by the four seasons: spring (March, April, May), summer (June, July, August), autumn (September, October, November) and winter (December, January, February) on the mortality of broiler chickens during their transport to the processing plants was determined in such a way that for the individual seasons for the whole monitored period, the total numbers of transported chickens and the total numbers of chickens having died were determined and mortality in percentages were calculated for the period from 2009 to 2014 .

In order to assess the impact of ambient temperature on the mortality of broiler chickens during their transport to the processing plants, ambient temperatures for individual transports were determined in cooperation with the Czech Hydrometeorological Institute. The Czech Hydrometeorological Institute collects data on meteorological and climatological measurements from its network of 802 stations located over the territory of the Czech Republic. The methods of measurement are unified, the ambient air temperature is measured at $2 \mathrm{~m}$ above ground level. Retrospective data on ambient air temperatures related to times and locations of transports monitored in our study were obtained from the archives of the Czech Hydrometeorological Institute. The ambient temperature 
under which the transports were carried out ranged from -6 to $21^{\circ} \mathrm{C}$ in the monitored period. For the purposes of our study, all broiler transports were divided into intervals of $6^{\circ} \mathrm{C}$ to $-3.1^{\circ} \mathrm{C},-3^{\circ} \mathrm{C}$ to $-0.1^{\circ} \mathrm{C}, 0^{\circ} \mathrm{C}$ to $2.9^{\circ} \mathrm{C}, 3^{\circ} \mathrm{C}$ to $5.9^{\circ} \mathrm{C}$, $6^{\circ} \mathrm{C}$ to $8.9^{\circ} \mathrm{C}, 9^{\circ} \mathrm{C}$ to $11.9^{\circ} \mathrm{C}, 12^{\circ} \mathrm{C}$ to $14.9^{\circ} \mathrm{C}, 15^{\circ} \mathrm{C}$ to $17.9^{\circ} \mathrm{C}$, and $18^{\circ} \mathrm{C}$ to $21^{\circ} \mathrm{C}$. For these intervals, the numbers of transported chickens and the numbers of chickens having died were recorded in absolute numbers and mortality levels in percentages were calculated for the period from 2009 to 2014.

Data were analysed using the statistical package Unistat v. 6.5. (Unistat Ltd., London, England). Statistical comparisons between the frequencies of the categorical variables of interest were performed with the Chi-square test (with Yates correction) within the $2 \times 2$ Contingency table procedure. When the frequencies in the contingency table were lower than 5, a Fisher exact test was used instead of Chi-square test (Zar, 1999). Data concerning transportrelated mortality rates in broiler chickens were compared between individual years and transport distances monitored, and also differences in mortality rates among seasons of the year were tested for the whole period from 2009 to 2014. Data concerning mean mortality rates in broilers as affected by the ambient temperature for the entire period monitored in the study were compared by a one-way analysis of variance and subsequently by a Tukey-HSD (honestly significant difference) test (Zar, 1999) as a post hoc test for pairwise comparisons. To assess a trend in mortality rates during monitored years, a Spearman rank correlation coefficient (Zar, 1999) including its significance was calculated. A p value of 0.05 in tests was considered significant.

\section{RESULTS}

The numbers of broiler chickens transported to poultry processing plants in the Czech Republic and the numbers of birds dying as a result of their transport for monitored

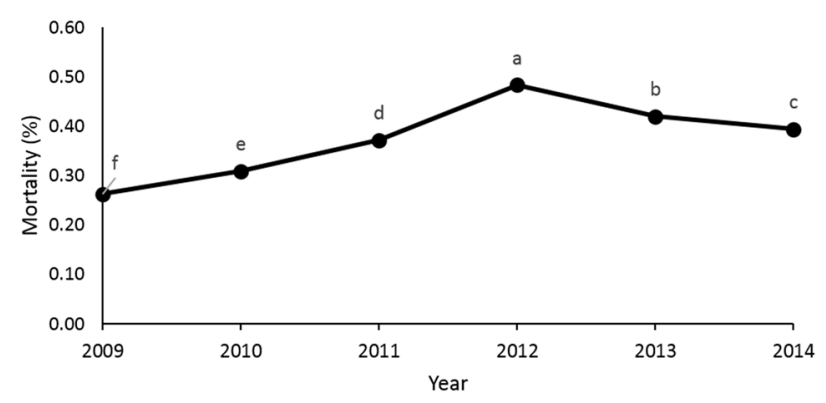

Figure 1. Trends in the transport-related mortality in broiler chickens in the period from 2009 to $2014 .{ }^{\mathrm{a}-\mathrm{f}}$ Mortality in columns with different superscripts differ significantly $(\mathrm{p}<0.001)$.

distances are given in Table 1. As follows from Table 1, considerable numbers of birds died as a result of their transport to poultry processing plants every year in the Czech Republic. While the total numbers of birds transported for slaughter in the Czech Republic were decreasing in the monitored period, the numbers of birds dying as a result of their transport to processing plants varied widely and statistically highly significant $(p<0.001)$ differences were found when comparing transport-related mortality rates in individual years. The trend in the transport-related mortality in broiler chickens in the period from 2009 to 2014 is shown in Figure 1. The lowest mortality was found in $2009(0.26 \%)$ whereas the highest mortality in those transported for slaughter was in $2012(0.48 \%)$. Subsequently, a significant $(\mathrm{p}<0.001)$ decline in transport-related mortality rates was observed in $2013(0.42 \%)$ and $2014(0.40 \%)$ but the mortality rates at the end of the monitored period still exceeded the rates recorded from 2009 to 2011. A significant positive correlation $(r=0.77, p=0.04)$ was found between mortality rates and monitored years in broiler chickens indicating an increasing tendency in broiler chicken losses during the monitored period.

The transport-related mortality of broiler chickens for transport distances monitored in our study is presented in Figure 2. A statistically highly significant $(\mathrm{p}<0.001)$ impact

Table 1. The numbers of broiler chickens transported to poultry processing plants and numbers of birds dying as a result of their transport for monitored distances

\begin{tabular}{llcccccc}
\hline $\begin{array}{c}\text { Distance } \\
(\mathrm{km})\end{array}$ & & 2009 & 2010 & 2011 & 2012 & 2013 & 2014 \\
\hline$<50$ & Transported & $58,826,352$ & $50,891,453$ & $30,075,711$ & $31,468,375$ & $30,088,077$ & $46,575,721$ \\
& Dead & 135,259 & 124,991 & 84,500 & 123,082 & 123,768 & 229,279 \\
\multirow{2}{*}{$51-100$} & Transported & $38,732,930$ & $36,476,661$ & $38,241,324$ & $39,037,406$ & $37,473,442$ & $29,992,569$ \\
& Dead & 92,976 & 93,501 & 119,231 & 165,148 & 129,714 & 85,840 \\
\multirow{2}{*}{$101-200$} & Transported & $28,170,894$ & $32,508,275$ & $33,088,714$ & $36,249,859$ & $32,417,590$ & $26,562,746$ \\
& Dead & 97,043 & 133,545 & 152,125 & 212,670 & 158,559 & 92,370 \\
\multirow{2}{*}{$201-300$} & Transported & $1,847,896$ & $3,801,381$ & $8,879,882$ & $7,593,103$ & $8,086,721$ & $4,446,363$ \\
& Dead & 9,889 & 29,055 & 53,276 & 51,977 & 41,482 & 16,612 \\
$>300$ & Transported & 60,890 & 118,338 & 379,577 & 201,814 & 241,359 & 202,986 \\
& Dead & 427 & 1,444 & 2,970 & 1,232 & 1,344 & 1,266 \\
\hline
\end{tabular}




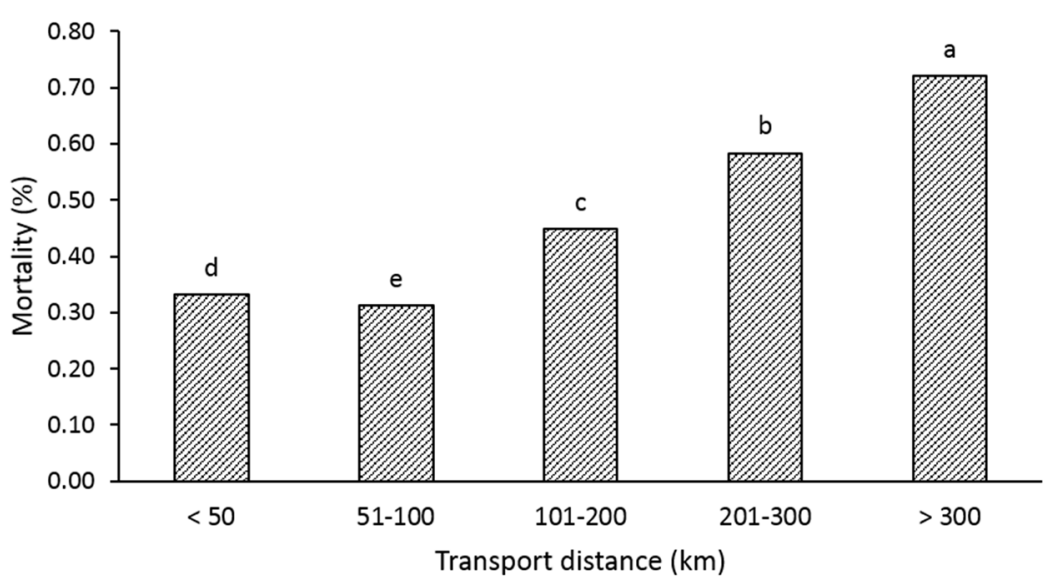

Figure 2. Transport-related mortality of broiler chickens as affected by transport distance. ${ }^{\text {a-e }}$ Mortality in columns with different superscripts differ significantly $(\mathrm{p}<0.001)$.

of the transport distance on the transport-related mortality in broiler chickens was found. The lowest mortality $(0.31 \%)$ was found in broiler chicken flocks transported for distances from 51 to $100 \mathrm{~km}$, the longer distances were associated with significantly $(\mathrm{p}<0.001)$ increasing death losses with the greatest losses $(0.72 \%)$ recorded for distances exceeding 300 $\mathrm{km}$. The only exception to the linear relationship between transport distance and chicken mortality was found in chickens transported for the shortest distances, i.e. up to 50 $\mathrm{km}$. Transport-related mortality rates for chicken transports over distances up to $50 \mathrm{~km}(0.33 \%)$ were greater $(\mathrm{p}<0.001)$ than the mortality rates recorded in transports over distances from 51 to $100 \mathrm{~km}$.

Transport-related mortality of broiler chickens as affected by the season of the year is shown in Figure 3. Statistically highly significant $(\mathrm{p}<0.001)$ differences were found when comparing transport-related mortality rates in individual seasons of the year. The greatest mortality $(0.55 \%)$ was associated with transports carried out in winter months whereas the lowest death losses $(0.30 \%)$ were found in chickens transported for slaughter in summer months.
Transports carried out in spring and summer were associated with greater $(p<0.001)$ mortality than summer transports but lower $(p<0.001)$ mortality than winter transports.

The impact of ambient temperature on transport-related mortality of broiler chickens is shown in Figure 4 . The transports carried out under ambient temperatures $-6^{\circ} \mathrm{C}$ to $3.1^{\circ} \mathrm{C}$ (the lowest temperatures observed in our study) were associated with the greatest dead losses of broiler chickens. The mortality related to these transports was significantly greater $(p<0.001)$ than to transports carried out under temperatures $-3^{\circ} \mathrm{C}$ and higher. The mortality related to transport of broiler chickens carried out under temperatures from $0^{\circ} \mathrm{C}$ to $21^{\circ} \mathrm{C}$ did not significantly differ.

\section{DISCUSSION}

Responses of birds to transportation are multi-component phenomena which involve many factors such as, bird condition at the barn (state of health prior to transportation), handling, loading, unloading, trailer design, loading density, environmental condition during transportation, trailer

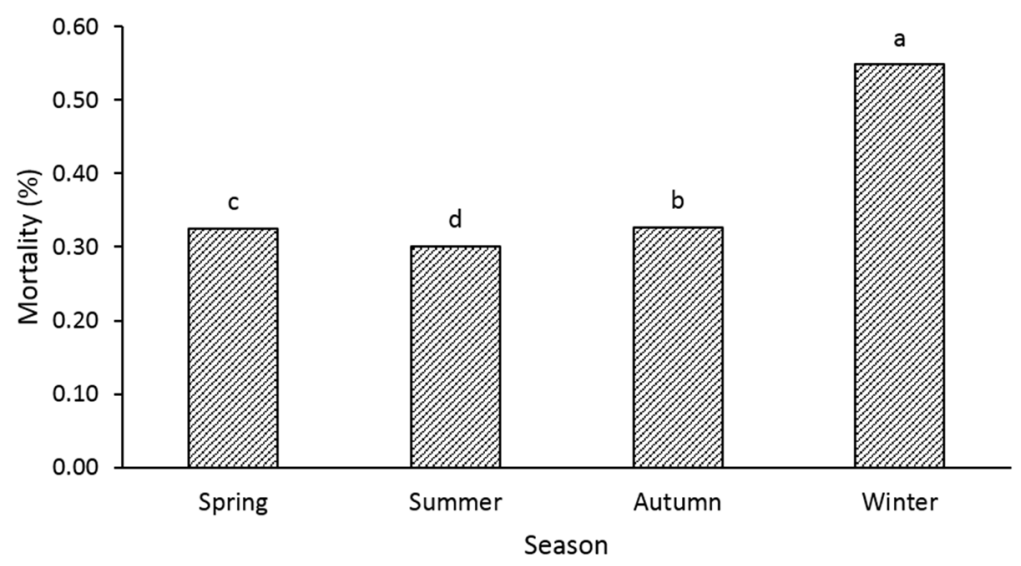

Figure 3. Transport-related mortality of broiler chickens as affected by the season of the year. ${ }^{\text {a-d }}$ Mortality in columns with different superscripts differ significantly $(\mathrm{p}<0.001)$. 


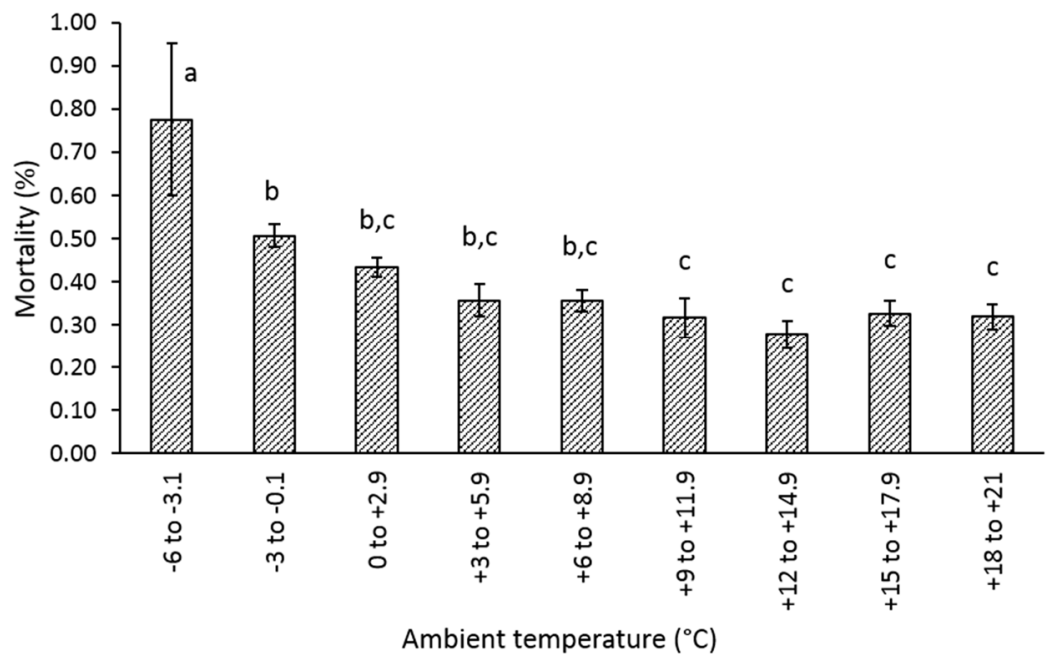

Figure 4. Transport-related mortality of broiler chickens as affected by the ambient temperature (mean \pm standard error of the mean). $a, b, c$ Means with different superscripts differ significantly $(p<0.05)$.

microclimate, transit duration, lairage duration and length of feed withdrawal (Schwartzkopf-Genswein et al., 2012). Generally, the preslaughter handling and transport are stressful operations that might affect welfare and could increase the numbers of deaths before slaughter (Vieira et al., 2011a). In recent years, broiler mortality during transport to the slaughterhouse has become a cause for concern because of animal welfare considerations and associated economic losses (Ali et al., 2008; Chauvin et al., 2011).

The high incidence of injuries and deaths during transport is associated with poor welfare and represents a considerable loss to the poultry industry (Vieira et al., 2011a). In some countries, closer scrutiny is exercised by inspectors when the number of broilers or end-of-cycle laying hens arriving DOA exceeds $1 \%$ and $4 \%$, respectively. The objectives of these closer inspections are to identify the possible causes for such high DOA rates, whether they are transport-related factors, animal disease or some other cause (Schwartzkopf-Genswein et al., 2012). Animal welfare guidelines and audit check lists have been developed by the USA National Chicken Council for broilers and broilerbreeders and state that when DOA's are over $0.5 \%$, a corrective action is required. Ritz et al. (2005) commented that a typical USA industry goal is for DOA percentages to be below $0.20 \%$. It seems that such a low mortality is usually only achieved for shorter journeys, though. Warriss et al. (1992) found the incidence of dead birds to be $0.16 \%$ for journeys lasting less than $4 \mathrm{~h}$, for longer journeys the incidence was $0.28 \%$. Vecerek et al. (2006) found a $0.15 \%$ death rate when broiler chickens were transported for slaughter over distances up to $50 \mathrm{~km}$. Transports of broilers over distances for more than $50 \mathrm{~km}$ were associated with DOA rates above $0.20 \%$. However, in Turkey even the shortest journeys having the total transportation duration below 120 minutes were associated with the mortality rate of $0.29 \%$ (Aral et al., 2014). In general, transport-related mortality averages in broiler chickens have been reported to vary from around $0.15 \%$ (Mitchell, 2006) to values as high as $1.4 \%$ (Knezacek et al., 2010) for transports carried out under differing conditions in different countries. In the present study, transport-related mortality of broiler chickens transported for slaughter in the Czech Republic was $0.37 \%$. Considering the fact that the total number of broiler chickens transported for slaughter exceed one hundred million birds every year, the $0.37 \%$ DOA incidence represents almost half a million dead birds every year. Death losses associated with the transport of chickens for slaughter found in our study were not only greater than the percentages reported by Ritz et al. (2005) as a USA industry goal but also than the actual transport-related mortality rates reported from other European countries. The level of transport-related mortality in broiler chickens in the Czech Republic is closer to values reported for broiler transports under adverse weather conditions than to values typical for the temperate climate regions of Western and Central Europe. And that is true even for transports over the shortest distances. Furthermore, the impact of increasing transport distance on increasing death losses associated with transport that has been published previously was demonstrated in this study too. The transport-related mortality ranged from $0.31 \%$ to $0.72 \%$, the increase approximately corresponding to increasing transport distance. Vieira et al. (2010) explain the rise in the losses related to the increasing of the distance travelled by a significant reduction in the ability of animals to maintain the necessary biological balance to cope with transport. However, rather than distance driven, it is the time spent on the vehicle, including stationary waiting time, which affects mortality (Nielsen et al., 2011). The time which broilers stay inside the 
transport trucks is variable during the loading and transport. These conditions vary according to each country, local climate conditions and with the type of transportation used (Vieira et al., 2010). Some journeys might last up to three hours and the birds are confined inside crates up to 12 hours, depending on the dynamic of the whole process (Aksit et al., 2006). Warriss et al. (1992) found that the average journey time for transporting broiler chickens to poultry processing plants was three hours and the maximum recorded was nine hours. In the Czech Republic, a maximum, nonextendible journey time of eight hours for the transport of animals destined for slaughter has been set since 2007, thus all journeys (for the legislative purposes "journey" means the entire transport operation from the place of departure to the place of destination) recorded in our study must have been carried out within this time limit. Even if considering only differences in mortality rates recorded in our study and no other aspects of welfare that can be expected to be adversely affected with prolonged journey duration, more than $100 \%$ increase in the mortality of chickens transported for longer distances $(<100 \mathrm{~km}$ vs $>300 \mathrm{~km})$ within an 8-hour time limit is alarming. It leads to the question of whether the establishment of a maximum 8-hour journey limit for animals transported in the European Union for the purpose of being slaughtered as declared by the European Parliament (2012) is sufficient to avoid bird suffering related to their transportation. Cockram (2007) suggests that more emphasis should be placed on the quality of the journey rather than focusing exclusively on the duration of a journey. Furthermore, in our study not only were longer journeys associated with greater mortality, but also chickens transported over the shortest distances (up to $50 \mathrm{~km}$ ) were more likely to die in comparison with birds transported for distances from 51 to $100 \mathrm{~km}$. Vosmerova et al. (2010) assumed that broiler chickens might be more stressed by a short transport because longer transportation periods provide sufficient time for broilers to recover partially from the stress associated with handling before loading and transport. As follows from the results published by Voslarova et al. (2011), broiler chickens need about one hour to recover partially from pretransport handling. Furthermore, the conditions under which those short transports are carried out might vary since most requirements of the Council Regulation (EC) 1/2005 of 22 December 2004 on the protection of animals during transport and related operations (European Council, 2005) aimed to ensure welfare of animals during transport do not apply to transport carried out by farmers, of their own animals, in their own means of transport for a distance of less than $50 \mathrm{~km}$ from their holding. This particular fact might be responsible for an increase in broiler mortality related to their transport over shorter distances that was found when comparing our current results with the results of an earlier study by Vecerek et al. (2006) analyzing transport-related mortality in the period before Council Regulation (EC) $1 / 2005$ entered into force. Therefore, the lack of legislation or industry standards (in the case of shorter transport distances) and inadequate enforcement or supervision to provide optimal conditions in transport might contribute to increasing transport-related mortality rates during short journeys as found in our study.

Climatic conditions belong to key factors affecting the DOA rates in most countries. Of the DOA evaluated by necropsy in the UK, 25\% were attributed to preexisting flock health status, $35 \%$ to catching, loading, and transport injuries, and $40 \%$ of the DOA were linked to heat or cold stress (Ritz et al., 2005). High temperature and relative humidity in the tropics are major concerns regarding broiler survival prior to slaughtering (Vieira et al., 2011b). A significant relationship between the time of year and mortality rate was reported by Tabbaa and Alshawabkeh (2000) in Jordan. The season significantly also influenced the transport-related mortality of broiler chickens in Italy, with higher incidence being observed during the summer (Petracci et al., 2006). Similarly in Canada, bird DOA rates were mainly associated with high summer ambient temperatures and the loading density of the trailers (Whiting et al., 2007). Previously, transportation studies were limited to those conducted in countries where winters are mild and the main problem with transportation occurs during the summer (Schwartzkopf-Genswein et al., 2012). The occurrence of DOA during hot summer months often exceeding $1.0 \%$ results in greater financial loss whereas cold-stress-induced mortality during transport is perceived by the US industry as too rare to be a serious issue, yet heat stress is widely recognized as a frequent impediment to maximal productivity (Ritz et al., 2005). Thus there is a large body of work focused on transportation and heat stress and its management. The risks of heat stress and measures to be taken to reduce transport-related mortality during hot summer months have been well described. The better management of transport during hot days can explain the decrease in death losses in summer months found in our study. Whereas for the period from 1997 to 2004 greater mortality of broiler chickens transported for slaughter in the Czech Republic was reported in both summer and winter months in comparison to transports carried out in spring and autumn (Vecerek et al., 2006), the current study found the summer months to be those with the lowest death losses. Only recently, attention has shifted to the assessment of the effects of cold temperature transportation on bird welfare and meat quality (Schwartzkopf-Genswein et al., 2012). Despite the fact that no extreme temperatures were recorded in the winter seasons monitored in our study (average ambient temperature ranging from $-1.95^{\circ} \mathrm{C}$ to $\left.-0.43^{\circ} \mathrm{C}\right)$, the greatest mortality $(0.55 \%)$ was associated with transports carried out in winter months. In countries where the winter season is 
more severe the death losses related to winter transports can be even more pronounced. Much higher DOA rates $(0.7 \%$ to $1.4 \%$ ) were reported for journeys conducted during a Saskatchewan winter in Western Canada (Knezacek et al., 2010). Winter transportation was reported to have a glycogenolytic effect on the muscle by imposing acute demands on energy metabolism, which in turn affects the $\mathrm{pH}_{\mathrm{u}}$ and subsequent meat quality of broilers causing meat with darker color and higher $\mathrm{pH}_{\mathrm{u}}$. Further study of the use of active ventilation during winter transportation in particular is needed in order to minimize temperature gradients and heat and moisture build up within the transport truck, to improve animal welfare and subsequent meat quality (SchwartzkopfGenswein et al., 2012). Our results suggest that extra measures should be taken for transports carried out under temperatures $-3^{\circ} \mathrm{C}$ and lower. But not only were winter transports found to be responsible for the greatest death losses in our study, a percentage of birds dying in relation to their transport for slaughter during winter months in the period monitored in our study (from 2009 to 2014) was greater in comparison with transports carried out in winter months in the period from 1997 to 2004 as recorded by Vecerek et al. (2006). The increase was seen also when comparing spring and autumn transports in the two periods.

In general, our study revealed greater transport-related mortality rates in broiler chickens transported for slaughter in the Czech Republic than expected when considering earlier studies. Furthermore, an increasing tendency in chicken losses during the monitored period was found. The fact that the mortality of broiler chickens transported to processing plants shows long-term increasing trends in the Czech Republic is particularly alarming when considering the same negative outcome was revealed by a previous study. Vecerek et al. (2006) found a statistically highly significant increase in transport losses in the period from 2001 to 2004 in comparison with the previous period from 1997 to 2000 in all distance categories monitored within the study. For decades, broiler chickens have been selected for their rapid growth rate as well as for high carcass yields, with particular regard to the breast, and reared in intensive systems at high stocking density. These conditions lead to a worsening of the welfare status of birds (Meluzzi and Sirri, 2009). Similar welfare issues affect intensively-housed birds worldwide, these include rapid growth rates, predisposing birds to heart and leg problems, especially ascites and sudden death syndrome, and high stocking densities, which inhibit locomotion and environmental exploration, predisposing birds to contact dermatitis (Robins and Phillips, 2011). The impaired health status of the chickens may subsequently reduce their ability to cope with the transport stress. Broiler chickens selectively bred to achieve slaughter weight in the shortest time are known to be more susceptible to stress than are slower growing domestic fowl (Sandercock et al., 2006).
In Europe, a specific directive for the protection of broiler chickens was adopted in 2007 in order to address the welfare problems in intensive farming systems. However, the current findings contradict the success of recent efforts to reduce the negative consequencies of decades of selecting broiler chickens for rapid growth rate on bird health in the European Union by the introduction of new legal regulations; these aimed to improve welfare standards both on farms (Council Directive 2007/43/EC of 28 June 2007 laying down minimum rules for the protection of chickens kept for meat production, European Council, 2007) and in transit (Council Regulation (EC) 1/2005 of 22 December 2004 on the protection of animals during transport and related operations, European Council, 2005). Increasing transport-related mortality is either the result of widespread non-compliance with regulations or industry standards and inadequate enforcement or supervision to provide optimal conditions, or the fact that the current legislation is still not effective. Closer scrutiny should be exercised by official authorities at poultry processing plants to identify the specific factors leading to mortality. Subsequently, practical guidelines to improve the welfare of the birds in transit should be adopted.

In conclusion, the high incidence of deaths during transport for slaughter is associated with poor welfare and represents a considerable loss to the poultry industry. In addition, the effect of transportation does not stop at slaughter, but affects the conversion of muscle to meat and the resultant meat quality parameters such as color, texture, and related protein functionality that could have negative effects on consumer acceptability and processing functionality of further processed products, which in turn can cause additional losses to the industry (SchwartzkopfGenswein et al., 2012). The mortality of broiler chickens being transported to processing plants shows a long-term increasing tendency over the last two decades. Further research should focus on identification of specific factors leading to such high and growing mortality rates and developing practical guidelines to improve the welfare of the birds in transit accordingly. Many factors could influence the effect of transportation on welfare, among which the microclimate within the transportation truck was reported as the major cause of mortality followed by loading density, bird size, age, state of health, transportation duration and distance, lairage prior to slaughter and management factors (Schwartzkopf-Genswein et al., 2012). Post-mortem assessment of birds DOA at the slaughterhouse has revealed that $40 \%$ of birds die from thermal stress due to uneven ventilation of the truck and failures in thermoregulation of birds (Mitchell and Kettlewell, 1998; Kettlewell et al., 2000). If some birds are sufficiently stressed to die, many more will be stressed close to their capacity to survive and have compromised welfare (Weeks, 2014). Concentrations of some hormones, enzymes or metabolites such as cortisol, 
corticosterone, creatine kinase and glucose could be indicative of the level of stress and muscle damage in broilers (Schwartzkopf-Genswein et al., 2012). According to Weeks (2014), it is feasible by applying existing knowledge and best practice to reduce losses in transit by at least half of current mean levels.

\section{CONFLICT OF INTEREST}

We certify that there is no conflict of interest with any financial organization regarding the material discussed in the manuscript.

\section{REFERENCES}

Aksit, M., S. Yalcin, S. Ozkan, K. Metin, and D. Ozdemir. 2006. Effects of temperature during rearing and crating on stress parameters and meat quality of broilers. Poult. Sci. 85:18671874.

Ali, S., G. H. Kang, and S. T. Joo. 2008. A review: Influences of pre-slaughter stress on poultry meat quality. Asian Australas J. Anim. Sci. 21:912-916.

Alshawabkeh, K. and M. J. Tabbaa. 1997. Factors affecting mortality and losses during transportation of broiler chickens from farms to processing plants in Jordan. Dirasat Agric. Sci. 24:53-61.

Aral, Y., M. S. Arikan, A. C. Akin, C. Y. Kaya Kuyululu, S. C. Guloglu, and E. Sakarya. 2014. Economic losses due to live weight shrinkage and mortality during the broiler transport. Ankara Univ. Vet. Fak. Derg. 61:205-210.

Bianchi, M., M. Petracci, and C. Cavani. 2006. The influence of genotype, market live weight, transportation, and holding conditions prior to slaughter on broilers breast meat color. Poult. Sci. 85:123-128.

Chauvin, C., S. Hillion, L. Balaine, V. Michel, J. Peraste, I. Petetin, C. Lupo, and S. Le Bouquin. 2011. Factors associated with mortality of broilers during transport to slaughterhouse. Animal 5:287-293.

Cockram, M. S. 2007. Criteria and potential reasons for maximum journey times for farm animals destined for slaughter. Appl. Anim. Behav. Sci. 106:234-243.

European Parliament. 2012. Declaration of the European Parliament of 15 March 2012 on the establishment of a maximum 8-hour journey limit for animals transported in the European Union for the purpose of being slaughtered. Off. J. Eur. Union C81E:25.

European Council. 2005. Council Regulation (EC) No $1 / 2005$ of 22 December 2004 on the protection of animals during transport and related operations and amending Directives 64/432/EEC and 93/119/EC and Regulation (EC) No 1255/97. Off. J. Eur. Union L3:1-44.

European Council. 2007. Council Directive 2007/43/EC of 28 June 2007 laying down minimum rules for the protection of chickens kept for meat production. Off. J. Eur. Union L182:19-28.

Fries, R. and A. Kobe. 1992. Data of flocks obtained in poultry meat processing (broilers). Dtsch. Tierarztl. Wochenschr. 99:500-504.

Gregory, N. G. and S. D. Austin. 1992. Causes of trauma in broilers arriving dead at poultry-processing plants. Vet. Rec. 131:501-
503.

Knezacek, T. D., A. A. Olkowski, P. J. Kettlewell, M. A. Mitchell, and H. L. Classen. 2010. Temperature gradients in trailers and changes in broiler rectal and core body temperature during winter transportation in Saskatchewan. Can. J. Anim. Sci. 90:321-330.

Kettlewell, P. J., R. P. Hoxey, and M. A. Mitchell. 2000. Heat produced by broiler chickens in a commercial transport vehicle. J. Agric. Eng. Res. 75:315-326.

Meluzzi, A. and F. Sirri. 2009. Welfare of broiler chickens. Ital. J. Anim. Sci. 8:161-173.

Mitchell, M. A. 2006. Influence of pre-slaughter stress on animal welfare and processing efficiency. Worlds Poult. Sci. J. 62:254.

Mitchell, M. A. and P. J. Kettlewell. 1998. Physiological stress and welfare of broiler chickens in transit: Solutions not problems! Poult. Sci. 77:1803-1814.

Nielsen, B. L., L. Dybkjaer, and M. S. Herskin. 2011. Road transport of farm animals: Effects of journey duration on animal welfare. Animal 5:415-427.

Nijdam, E., P. Arens, E. Lambooij, E. Decuypere, and J. A. Stegeman. 2004. Factors influencing bruises and mortality of broilers during catching, transport, and lairage. Poult. Sci. 83:1610-1615.

Oba, A., M. de Almeida, J. W. Pinheiro, E. I. Ida, D. F. Marchi, A. L. Soares, and M. Shimokomaki. 2009. The effect of management of transport and lairage conditions on broiler chicken breast meat quality and DOA (Death on Arrival). Braz. Arch. Biol. Technol. 52:205-211.

Petracci, M., M. Bianchi, C. Cavani, P. Gaspari, and A. Lavazza. 2006. Preslaughter mortality in broiler chickens, turkeys, and spent hens under commercial slaughtering. Poult. Sci. 85:16601664.

Ritz, C. W., A. B. Webster, and M. Czarick. 2005. Evaluation of hot weather thermal environment and incidence of mortality associated with broiler live haul. J. Appl. Poult. Res. 14:594602.

Robins, A., and C. J. C. Phillips. 2011. International approaches to the welfare of meat chickens. Worlds Poult. Sci. J. 67:351-369.

Sandercock, D. A., R. R. Hunter, M. A. Mitchell, and P. M. Hocking. 2006. Thermoregulatory capacity and muscle membrane integrity are compromised in broilers compared with layers at the same age or body weight. Br. Poult. Sci. 47:322-329.

Schwartzkopf-Genswein, K. S., L. Faucitano, S. Dadgar, P. Shand, L. A. González, and T. G. Crowe. 2012. Road transport of cattle, swine and poultry in North America and its impact on animal welfare, carcass and meat quality: A review. Meat Sci. 92:227243.

Tabbaa, M. J. and K. Alshawabkeh. 2000. Some factors affecting preslaughtering mortality and damage to broilers and interaction during transportation to processing plants. Dirasat Agric. Sci. 27:375-384.

Vecerek, V., S. Grbalova, E. Voslarova, B. Janackova, and M. Malena. 2006. Effects of travel distance and the season of the year on death rates of broilers transported to poultry processing plants. Poult. Sci. 85:1881-1884.

Vieira, F. M. C., I. J. O. da Silva, J. A. D. Barbosa Filho, and A. M. C. Vieira. 2010. Productive losses on broiler preslaughter operations: effects of the distance from farms to abattoirs and of lairage time in a climatized holding area. R. Bras. Zootec. 39:2471-2476. 
Vieira, F. M. C., I. J. O. Silva, J. A. D. Barbosa Filho, A. M. C. Vosmerova, P., J. Chloupek, I. Bedanova, P. Chloupek, K. Vieira, and D. M. Broom. 2011a. Preslaughter mortality of broilers in relation to lairage and season in a subtropical climate. Poult. Sci. 90:2127-2133.

Vieira, F. M. C., I. J. O. da Silva, J. A. D. Barbosa, A. M. C. Vieira, V. C. Rodrigues-Sarnighausen, and D. D. Garcia. 2011b. Thermal stress related with mortality rates on broilers' preslaughter operations: a lairage time effect study. Cienc. Rural 41:1639-1644.

Voslarova, E., B. Janackova, L. Rubesova, A. Kozak, I. Bedanova, L. Steinhauser, and V. Vecerek. 2007. Mortality rates in poultry species and categories during transport for slaughter. Acta Vet. Brno 76:101-108.

Voslarova, E., P. Chloupek, P. Vosmerova, J. Chloupek, I. Bedanova, and V. Vecerek. 2011. Time course changes in selected biochemical indices of broilers in response to pretransport handling. Poult. Sci. 90:2144-2152. Kruzikova, J. Blahova, and V. Vecerek. 2010. Changes in selected biochemical indices related to transport of broilers to slaughterhouse under different ambient temperatures. Poult. Sci. 89:2719-2725

Warriss, P. D., E. A. Bevis, S. N. Brown, and J. E. Edwards. 1992. Longer journeys to processing plants are associated with higher mortality in broiler-chickens. Br. Poult. Sci. 33:201-206.

Weeks, C. A. 2014. Poultry handling and transport. In: Livestock Handling and Transport, (Ed. T. Grandin). Cabi Publishing, Wallingford, England. pp. 378-398.

Whiting, T. ., E. D. Mairead, and D. P. Rasali. 2007. Warm weather transport of broiler chickens in Manitoba. II. Truck management factors associated with death loss in transit to slaughter. Can. Vet. J. 48:148-154

Zar, J. H. 1999. Biostatistical Analysis. 4th edn. Prentice Hall, Upper Saddle River, NJ, USA. 